\title{
INVESTIGATION OF COPPER(I) SULPHIDE LEACHING IN OXIDATIVE HYDROCHLORIC ACID SOLUTION
}

\author{
Branislav Markovic ${ }^{1 *}$, Miroslav Sokic ${ }^{1}$, Željko Kamberović ${ }^{2}$, \\ Dragana Živković, Nada Štrbac ${ }^{3}$, Vaso Manojlović ${ }^{1}$ \\ ${ }^{I}$ Institute for Technology of Nuclear and Other Mineral Raw Materials, \\ Bulevar Franša d'Eperea 86, 11000 Belgrade, Serbia \\ ${ }^{2}$ Faculty of Technology and Metallurgy, University of Belgrade, \\ Karnegijeva 4, 11120 Belgrade, Serbia \\ ${ }^{3}$ Technical Faculty, University of Belgrade, Vojske Jugoslavije 12, \\ 19210 Bor, Serbia
}

Received 30.09.2015

Accepted 13.11.2015

\begin{abstract}
Present work is focused on the copper (I) sulphide leaching with sodium chloride in hydrochloric acid solution and with introduction of gaseous oxygen. Chemical reactions of leaching and their thermodynamic probabilities are predicted based on the literature data and products which were formed during the process and the overall leaching reaction was defined. The influence of temperature and time on the leaching degree of copper was experimentally determined. The quantity of dissolved copper increases with the increase of both investigated parameters. Elemental sulphur was formed as the main leaching product, precipitated at the particle surfaces and chloride ions have a role to disrupt the creation of this passive layer.

Key words: leaching; copper (I) sulphide; hydrochloric acid; sodium chloride
\end{abstract}

\section{Introduction}

Hydrometallurgical processes provide an efficient method for processing of lowgrade complex ores. In spite of the fact that in pyrometallurgical processes, the sulphide sulphur is used as fuel, hydrometallurgical processes are increasingly popular because of environmental protection. Concerns over air pollution and the environmental problem of acid rain have made governments worldwide tighten their regulations regarding the emission of sulphur dioxide. The focus is on the production of elemental sulphur and soluble copper sulphate [1].

\footnotetext{
*Corresponding author: Branislav Marković,b.markovic@itnms.ac.rs
} 
Leaching of copper (I) sulphide has been the subject of many investigations [26], including leaching under high pressure and atmospheric pressure. The process of copper matte leaching under high pressure conditions, in both acidic and alkaline solutions, necessitates high capital and operation costs.

As early as 1933, Sullivan [2] showed that, in an acidified ferric sulphate leachant, chalcocite $\left(\mathrm{Cu}_{2} \mathrm{~S}\right)$ dissolved in a two-stage process with covellite $(\mathrm{CuS})$ as the solid product formed at the end of the first stage. In the second stage, the process occurs through the formation of elemental sulphur. Fisher and Roman [5] reported that oxygenated sulphuric acid solutions containing halogen anions $\left(\mathrm{Cl}^{-}\right.$or $\left.\mathrm{Br}^{-}\right)$were very effective in the leaching of chalcocite. Subsequently, Roman and Benner [7] put forward the proposal that sulphuric acid containing chloride ions could be a useful leachant for copper sulphides and the advantages of using mixed chloride-sulphate acid leachants for chalcocite-type minerals were recognised. Cho [8] investigated leaching of chalcocite in hypochlorous acid and found that the leaching rate was $\mathrm{pH}$ dependent. The Broken Hill Associated Smelters (BHAS) in Port Pirie, South Australia [9], developed a process for treating a lead-refining by-product, copper-lead sulphide matte, using an oxygenated acid solution containing both sulphate and chloride ions. The leaching process with oxygen takes place at $85^{\circ} \mathrm{C}$, while copper dissolves and lead remains in the solid residue as lead sulphate together with elemental sulphur. The cupric ions are subsequently transferred into an electrolyte sulphate solution. Cheng and Lawson [10] investigated the kinetics of leaching chalcocite in acidic oxygenated sulphate-chloride solutions and found that the process occurred in two stages, which was very similar to the conclusions of Sullivan [2]. The same authors Cheng and Lawson [11] have leached white metal (containing $\mathrm{Cu}_{2} \mathrm{~S}$ ) and reported the same results as in the previous investigation [10]. This proves that the process occurs through the formation of $\mathrm{CuS}$ and elemental sulphur, and that the role of chloride ions is to prevent the formation of a coherent, passivating sulphur layer on the particle surface.

The results of copper (I) sulphide leaching in a solution of $\mathrm{NaCl}$ in the presence of oxygen and $\mathrm{HCl}$ are shown in this paper.

\section{Leaching mechanism}

Many research results [10-13] show that the leaching of copper-containing minerals occurs in two stages. In the first leaching stage, as the cuprous ions diffuse to the particle surface, a series of intermediate solid products are formed before 'stable' covellite is produced. During the second leaching stage, covellite reacts, leaving a shell of elemental sulphur surrounding a reducing core of unreacted covellite [11].

In chloride solutions, additional reactions of complexation are very important [15]. In cupric chloride solutions, $\mathrm{Cu}^{2+}, \mathrm{CuCl}^{+}$or $\mathrm{CuCl}_{2}{ }^{-}$are observed, and the last is predominant at high chloride ion concentrations [16]. The distribution is somewhat controversial: other authors suppose also the presence of $\mathrm{CuCl}_{3}{ }^{-}$and $\mathrm{CuCl}_{4}{ }^{-}$[17]. The increased solubility of cuprous chloride when chloride ions are added is explained by the successive formation of $\mathrm{CuCl}_{2}^{-}, \mathrm{CuCl}_{3}^{2-}$, and finally, $\mathrm{CuCl}_{4}^{3-}$. In the conditions of high oxygen potentials and low $\mathrm{pH}$ values, $\mathrm{Cu}^{2+}$ ions will be stable.

On the basis of literature data [10-17] and the products in the solution, as well as in the solid residue of leaching, determined by X-ray analysis, and having in mind that all reactions occurring in electrolyte solution are electrochemical, the reaction in the 
first leaching stage in the $\mathrm{Cu}_{2} \mathrm{~S}-\mathrm{NaCl}-\mathrm{HCl}-\mathrm{O}_{2}-\mathrm{H}_{2} \mathrm{O}$ system can be presented as follows:

Anodic reaction:

$\mathrm{Cu}_{2} \mathrm{~S}=\mathrm{Cu}^{2+}+\mathrm{CuS}+2 \mathrm{e}^{-}$

Cathodic reaction:

$2 \mathrm{H}^{+}+1 / 2 \mathrm{O}_{2}+2 \mathrm{e}^{-}=\mathrm{H}_{2} \mathrm{O}$

Overall reaction:

$\mathrm{Cu}_{2} \mathrm{~S}+2 \mathrm{H}^{+}+1 / 2 \mathrm{O}_{2}=\mathrm{Cu}^{2+}+\mathrm{CuS}+\mathrm{H}_{2} \mathrm{O}$

The reaction in the second leaching stage is also electrochemical:

Anodic reaction:

$\mathrm{CuS}=\mathrm{Cu}^{2+} \mathrm{S}^{0}+2 \mathrm{e}^{-}$

Cathodic reaction:

$2 \mathrm{H}^{+}+1 / 2 \mathrm{O}_{2}+2 \mathrm{e}^{-}=\mathrm{H}_{2} \mathrm{O}$

Overall reaction:

$\mathrm{CuS}+2 \mathrm{H}^{+} 1 / 2 \mathrm{O}_{2}=\mathrm{Cu}^{2+} \mathrm{S}^{0}+\mathrm{H}_{2} \mathrm{O}$

The overall reaction for the first and the second stage is derived from the above reactions

$\mathrm{Cu}_{2} \mathrm{~S}+4 \mathrm{H}^{+}+\mathrm{O}_{2}=2 \mathrm{Cu}^{2+}+\mathrm{S}^{0}+2 \mathrm{H}_{2} \mathrm{O}$

\section{Experiments}

All leaching experiments were carried out in a glass reactor equipped with a teflon stirrer, condenser, thermometer, glass funnel for adding the solid sample and a sampling device (Fig. 1.).

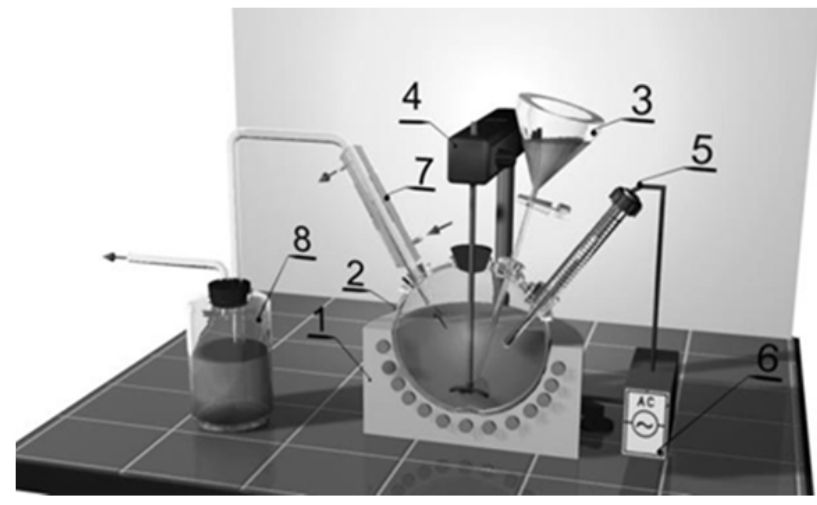

Fig. 1. Experimental set-up for the leaching process at atmospheric pressure: 1-electroresistant callote, 2-glass reactor, 3-glass funnel, 4-electro-powered stirrer, 5-mercury contact thermometer, 6-cut off relay, 7-condenser, 8-absorber 
This set-up provides stable hermetic conditions and allows heating at constant temperature. Before leaching was started, the solution of $\mathrm{NaCl}$ and $\mathrm{HCl}$ was oxygenated for $30 \mathrm{~min}$ at the selected temperature, then, the solid sulphide was added. From the moment of adding the solid sample, reaction time was calculated, with solution sample being withdrawn at regular intervals for chemical analysis. The amount of leached copper was determined by Atomic absorption spectroscopy (AAS, Perkin Elmer). The solid residues were filtered, washed with distilled water, dried and their phase content was determined by X-ray analysis using diffractometer (PHILIPS PW-1710).

The following parameters were studied: temperature $\left({ }^{\circ} \mathrm{C}\right)$ : $55-95$; stirring rate $\left(\mathrm{min}^{-1}\right)$ : 200-550; concentrations of $\mathrm{NaCl}$ and $\mathrm{HCl}\left(\mathrm{mol} / \mathrm{dm}^{3}\right): 0.2-0.75$; concentration of total chloride ions $\left(\mathrm{mol} / \mathrm{dm}^{3}\right): 0.25-0.75$; and phase ratio $(\mathrm{S}: \mathrm{L}): 10-30 \mathrm{~g} \mathrm{Cu}_{2} \mathrm{~S}$ in $1,2 \mathrm{~L}$ of the solution. Leaching times were in the range of 5 to $240 \mathrm{~min}$. Previous investigations [12] show that oxygen flow rate has no important influence on degree of copper leaching in acidic oxygenated chloride solutions, if the initial sample is finely sized. For that reason, in all leaching experiments, oxygen flow was $0.60 \mathrm{~L} / \mathrm{min}$.

\section{Experimental results and discussion}

For the investigations $\mathrm{Cu}$ (I) sulphide with $80.42 \%$ of $\mathrm{Cu}$ and $18.64 \%$ of $\mathrm{S}$ and the density of $5040 \mathrm{~kg} / \mathrm{m}^{3}$ was used. The sample's specific surface was $S_{o}=7481$ $\mathrm{m}^{2} / \mathrm{m}^{3}, S_{w}=1385 \mathrm{~m}^{2} / \mathrm{g}$, where $S_{o}$ and $S_{w}$ refer to external and internal porosity, respectively. Sodium chloride of $99.5 \%$ purity and $36.2 \%$ solution of $\mathrm{HCl}$ were used.

Fig. 2 shows the temperature dependence of $\mathrm{Cu}$ (I) sulphide leaching in an oxidised, acidic $0.5 \mathrm{M} \mathrm{HCl} / 0.5 \mathrm{M} \mathrm{NaCl}$ solution, when the stirring rate was $400 \mathrm{~min}^{-1}$ and phase ratio was $1200 \mathrm{~mL}: 20 \mathrm{~g} \mathrm{Cu}_{2} \mathrm{~S}$.

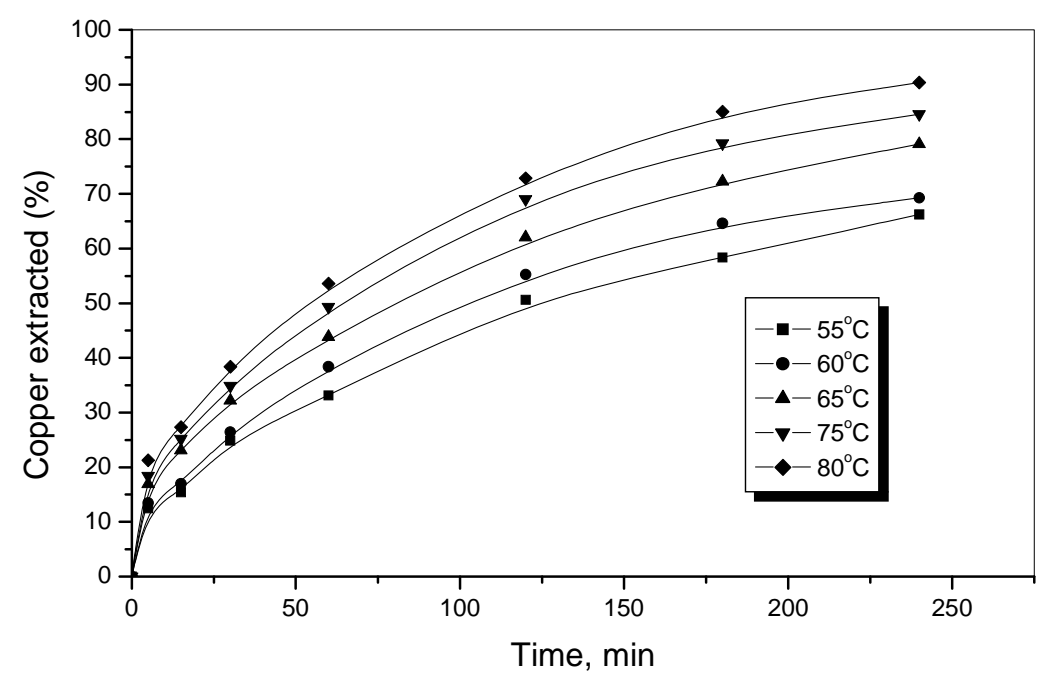

Fig. 2. Temperature dependence for $\mathrm{Cu}$ (I) sulphide leaching

A seen in Fig. 2 leaching is strongly influenced by temperature. A slower increase in the leaching degree is noticeable after $120 \mathrm{~min}$. This is probably due to the surface of $\mathrm{Cu}$ (I) sulphide particles being blocked by the reaction's solid products; 
resulting in a more difficult penetration of the reaction area into the centre of the $\mathrm{Cu}_{2} \mathrm{~S}$ grain. The maximum leaching degree was $90 \% \mathrm{Cu}$, after $240 \mathrm{~min}$ at $80^{\circ} \mathrm{C}$.

The X-ray diffraction analysis of obtained solid residue, was carried out (Fig. 3.) in order to investigate the products and the form they occur in during leaching, particularly sulphur, which is responsible for process mechanism. It revealed the presence of clearly formed crystals of elementary sulphur. Besides sulphur, the solid residue contains $\mathrm{Cu}_{2} \mathrm{Cl}(\mathrm{OH})_{3}$. These products form a solid layer on the reaction surface, which makes the diffusion of leaching reagents more difficult.

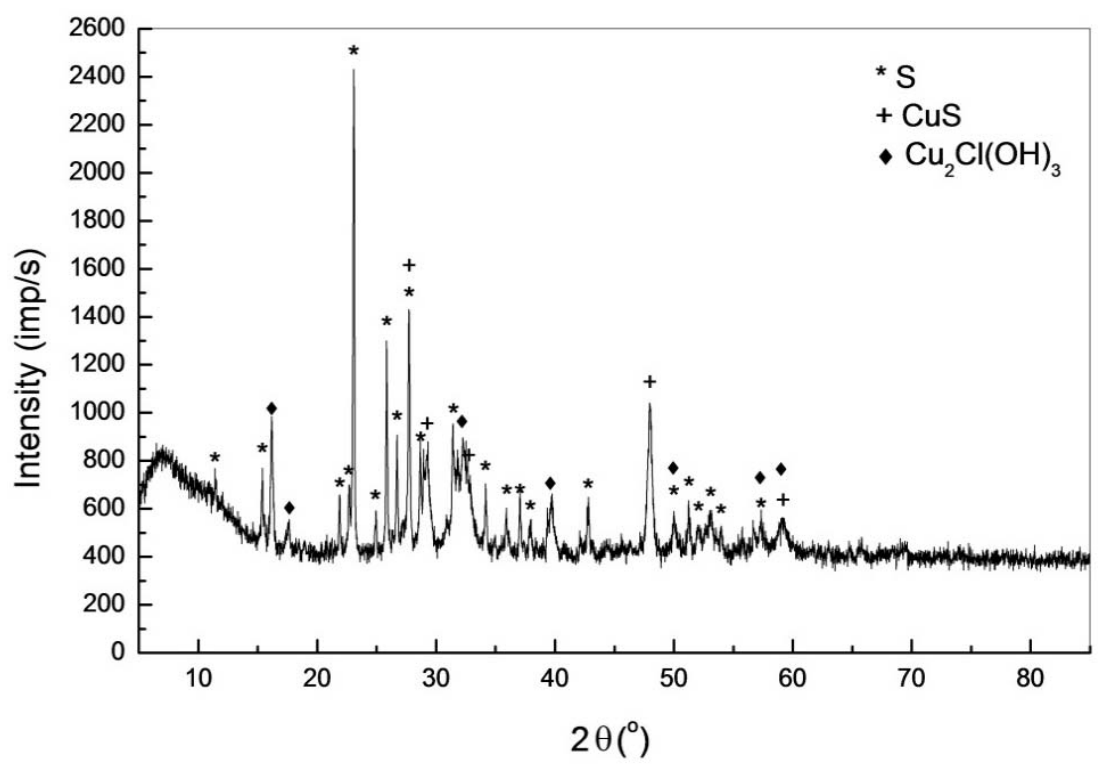

Fig. 3. X-ray of solid residue of leaching at $80^{\circ} \mathrm{C}$, stirring rate $400 \mathrm{~min}^{-1}$ in $0.5 \mathrm{~mol} / \mathrm{dm}^{3}$ $\mathrm{HCl} / 0.5 \mathrm{~mol} / \mathrm{dm}^{3} \mathrm{NaCl}$ solution.

\section{Conclusion}

From the results obtained in the study of copper (I) sulphide leaching by $\mathrm{NaCl}$ and $\mathrm{HCl}$ solution in the presence of gaseous oxygen, the following conclusions can be made:

(1) On the basis of literature data and the products formed during leaching and Xray analysis, it can be concluded that its chemistry mechanism is determined by the following overall reactions:

The first leaching stage: see Eq. (3)

The second leaching stage: see Eq. (6)

Overall reaction for both first and second leaching stage: see Eq. (7)

(2) The experimental study showed that high degree of leaching of copper could be achieved $(90 \%)$. The increase of temperature increases the degree of leaching of copper. 


\section{Acknowledgment}

The authors wish to acknowledge the financial support from the Ministry of Education, Science and Technological Development of the Republic of Serbia through the project TR34023.

\section{References}

[1] J.I. Jones, The Leaching of Chalcopyrite, PhD Thesis, Department of Metallurgy, University of British Columbia, May, 1974.

[2] J.D. Sullivan, Trans. Am. Inst. Min. Metall. 106 (1933) 515-547.

[3] I.H. Warren, Aust. J. Appl. Sci. 9 (1958) 36-51.

[4] W. Mulak, J. Niemiec, Rocz. Chem. 43 (1969) 1387- 1394.

[5] W.W. Fisher, R.J. Roman, The dissolution of chalcocite in oxygenated sulphuric acid solution, Circ. 112 State Bur. Mines Resources, New Mexico Inst. Min. Technol., 1971.

[6] J.A. King, A.R. Burkin, R.C.H. Ferreira, Leaching of chalcocite by acidic chloride solutions, in: A.R. Burkin (Ed)., Leaching and Reduction in Hydrometallurgy, Inst. Min. Metall., London, (1975) 36-45.

[7] R.J. Roman, B.R. Benner, Miner. Sci. Eng. 5 (1973) 3-24.

[8] E.H. Cho, J. Met. (1987) 18-20.

[9] R. Lal, J.H. McNicol, The BHAS copper leach plant. Techn. Pap. A87-1, Metall. Soc. AIME., Warrendale, PA, 1987.

[10] Y.C. Cheng, F. Lawson, Hydrometallurgy 27 (1991) 249-268.

[11] Y.C. Cheng, F. Lawson, ICHM 1992, Changsha, China, October 23-26, vol. 1.

[12] M.H. Mao, E. Peters, Acid pressure leaching of chalcocite, in: K. Osseo-Asare, J.D. Miller (Eds.), Hydrometallurgy: Research, Development and Plant Practice, Metall. Soc. AIME, Warrendale, PA, (1983) 243-260.

[13] N.E. Meadows, N.J. Ricketts, G.D.J. Smith, Oxygen leaching of copper-lead matte in acidic chloride / sulphate solutions, Research and Development in Extractive Metallurgy, Aust. Inst. Min. Metall., Adelaide Branch, (1987) 115-120.

[14] R.Ž. Vračar, I.S. Parezanović, K.P. Cerović, Hydrometallurgy 58 (2000) 261-267.

[15] K.G. Ashurst, The thermodynamics of the formation of chlorocomplexes of nickel and copper(II) in perchlorate medium. Nat. Inst. Metall., Johannesburg, S. Africa, Rep. 1712 (1975).

[16] M.J. Schwing-Weil, Bull. Soc. Chim. Fr. 3 (1973) 823-830.

[17] A. Fontana, J. Van Muylder, R. Winand, Hydrometallurgy 11 (1983) 297-314. 